\title{
COMUNICACIÓN
}

\section{A new nematode Hysterothylacium aetobatum from ray fish, Aetobatus narinari (Euphrasen)}

\author{
I. RAJYA LAKSHMI*
}

\begin{abstract}
The present paper reports a new species of a nematode of Aetobatus narinari caught off the Bay of Bengal at Visakhapatnam. It could be distinguished by body measurements, arrangement of papillae on the lips, length of intestinal caecum, position of vulva, number and arrangement of caudal papillae, position and size of spicules and shape of tail. The new species is named as Hysterothylacium aetobatum.
\end{abstract}

Key words: Hysterothylacium aetobatum n.sp., nematode, intestine, Aetobatus narinari, Visakhapatnam.

\section{INTRODUCTION}

The course of a survey of the parasites of marine eel fishes of Bay of Bengal (Visakhapatnam), a new species of a nematode Hysterothylacium aetobatum of the family Anisakidae Railliet et Henry, 1912 was recovered from the intestine of Aetobatus narinari. The new species is described in this paper and it has been shown that they have to be considered as constituting a new species.

\section{MATERIAL AND METHODS}

The host Aetobatus narinari was obtained from Bay of Bengal at Visakhapatnam.

Nematodes were fixed in hot $70 \%$ alcohol and were preserved in $10 \%$ glycerol. Glycerol and creosote were used to facilitate detailed examinations. For enface view examination the head of one male parasite was cut with a sharp blade and brought into the desired position under the cover glass using creosote on the slide.

All measurements are given in millimetres.

\section{OBSERVATIONS}

Family: Anisakidae Railliet et Henry, 1912

Genus: Hysterothylacium Ward and magath, 1917

Hystgerothylacium aetobatum n.sp.

(Figures 1 and 2)

Material: Two males and two females

Host: Aetobatus narinari (Euphrasen)

Location: Intestine

Locality: Visakhapatnam (Bay of Bengal), Andhra Pradesh, India

Type specimens: Specimens deposited in the Museum of the Zoology Department, Andhra University, Visakhapatnam, India.

Body medium sized, widens anteriorly and tapers down posteriorly. Cuticle thin, striations absent. The head carries three large lips, they are clearly separated from each other and the space

* Department of Zoology, Andhra University, Visakhapatnam-530 003A.P., India. 


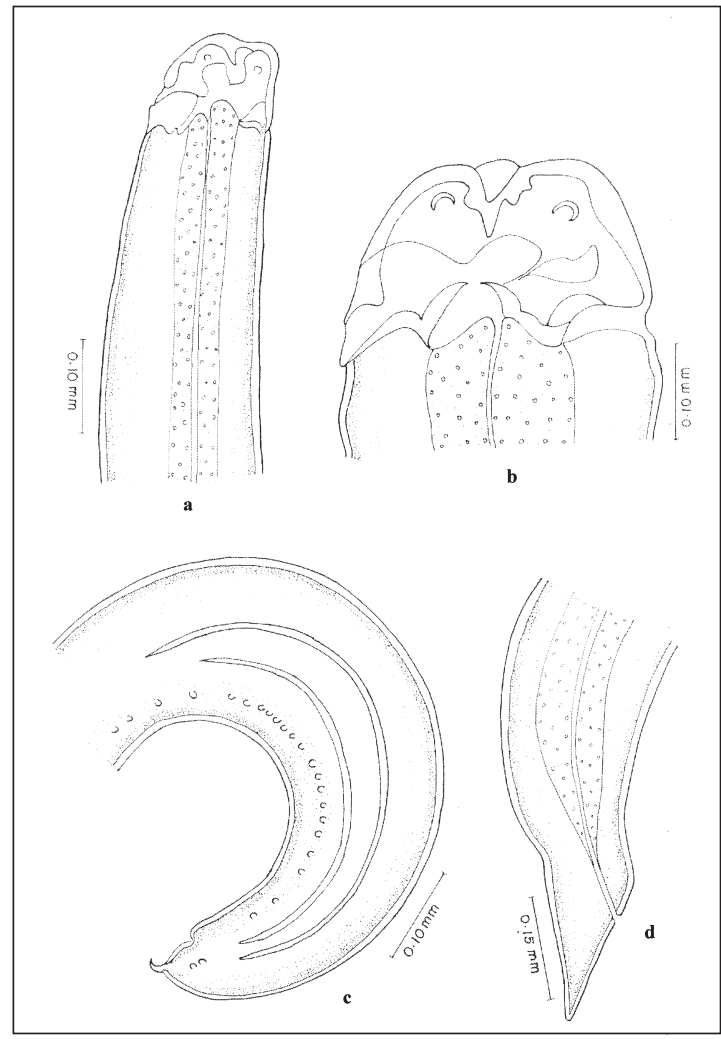

Figura 1. Hysterothylacium aetobatum n.s.p. a: Anterior end of male. b: Head of male - enlarged. c: Posterior end of male. d. Posterior end of female.

between the two adjacent lips is occupied by very prominent interlabia. Dorsal lip has two round ends which fit into the cavities of the two subventral lips. Interlabia large and covered with thick cuticle.

Oesophagus is divided into two portions, an anterior muscular portion and a posterior glandular portion. A large and posteriorly directed oesophageal appendix is given into the ventriculus. Intestine thick, long caecum is thrust out anteriorly. Excretory pore is situated at the level of nerve ring. Vulva equatorial. Tail conical in both sexes.

Male: Measures 18-19 length and maximum width 0.288-0.312. Body widest in the posterior region and narrowest just behind the lips. Head diameter 0.132-0.156. Nerve ring at 0/372-0.396 from the anterior end. Mouth is surrounded by three lips. Oesopahus measures 1.632-1.668 length $0.120-0.132$ width. Ventriculus 0.060 0.072 length $0.120-0.132$ width. Oesophageal

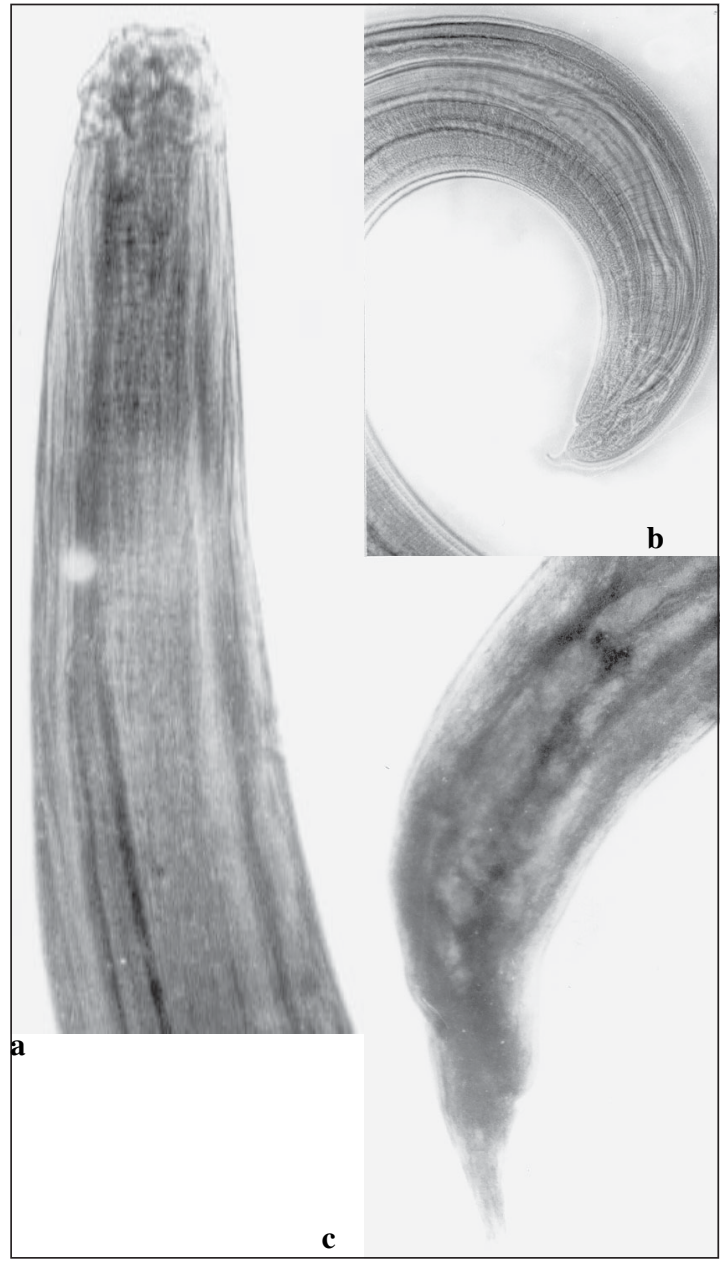

Figura 2. Hysterothylacium aetobatum n.s.p. a: Anterior end of male. b: Posterior end of male. c: Posterior end of female.

appendix $0.732-0.780$ and intestinal caecum 4.596-4.956.

Tail short, conical, 0.132-0.144 in length. Posterior end of male curved. Altogether 24 pairs of sessile papillae in caudal region. 22 pairs precloacal and 2 pairs postcloacal. Caudal alae absent. Spicules unequal, left spicuels 0.6840.708 and right spicule 0.792-0.828.

Female: Measures 20-21 in length with maximum width of $0.468-0.492$. Head diameter is $0.120-0.132$. Nerve ring at $0.432-0.456$ from anterior end. Mouth is surrounded by three lips. Oesophagus 1.872-1.920 length and 0.156-0.168 in width. Ventriculus 0.072-0.084 length, 0.1200.132 width. Oesophageal appendix 0.744-0.768 
and intestinal caecum 4.788-4.884 length.

Tail conical 0.252-0.276 long. Vulva 7-8 from head end. Eggs, spherical and 0.006-0.012 in diameter. Rectal glands absent.

\section{DISCUSSION}

Hysterothylacium was erected in $1917^{1}$. Dollfus $(1933)^{2}$ erected the genus Thynnascariss with same characters as Hysterothylacium ${ }^{2}$. Deardorff and Overstreet $(1980)^{3}$ examined the type specimen of $H$. brachurum and confirmed the Hysterothylacium as valid genus. The present specimens considered as Hysterothylacium and compared with hitherto described species of Hysterothylacium.

Hysterothylacium aetobatum n.sp. shows resemblance in unequal spicules to $H$. synpapillus $^{4} ; H$. ogcocephali ${ }^{3} H$. reliquens $^{3} ; H$. corrugatum $^{3} ; H$. aduncum ${ }^{5} ; H$. pelagicum ${ }^{6} ; H$. elurensis Rajyalakshmi and Vijaya Lakshmi, 1995; $H$. nellorensis ${ }^{7}$ and $H$. japonicum ${ }^{8}$ but differs from body measurements, type of striations on the cuticle, length of intestinal caecum, position and size of spicules, number and arrangement of caucal papillae, position of vulva and shape of tail in both sexes.

The new species differs in body measurements from $H$. incurvum ${ }^{3} ; H$. trichiuri $^{3} ; H$. fortalezae ${ }^{3}$; H. chaunaxi $^{3} ; H$. fabric ${ }^{9} ; H$. cornutum $^{6} ; H$. scomberoide $i^{6} ; H$. pseudotumbili ${ }^{10}$ and $H$. neocornutum ${ }^{11}$; H. krishnai $^{12}$ n.sp.; H. kiranii $^{13}$; H. carutti $^{14} ;$ H. longicaecum $^{15} ;$ H. rhamdiae ${ }^{16} ; \mathrm{H}$. channai $^{17} ; H$. punctati $^{18} ; H$. fossilii ${ }^{19} ; H$. narayanensis ${ }^{20} ; H$. patagonense $e^{21} ; H$. nipponense ${ }^{22} ; H$. geschei ${ }^{23}$ and $H$. physiculi ${ }^{24}$.

The present species has close resemblance to Hysterothylacium longicaecum in having a long intestinal caecum but differs from it in body size, location of nerve ring, size of the spicules, number and arrangement of caudal papillae and shape of tail in male, hence a new species is erected as $H$. aetobatum.

\section{REFERENCES}

1.- WARD H B, MAGATH T B. Notes on some nematodes from freshwater fishes. J Parasitol 1917; 3: 57-65.

2.- DOLLFUS R P H. Thynnascaris legendrei n.gen., n.sp. de l'estomac du German, Germoalalonge (Gmel). Bull Soc Zool France 1933; 58: 7-12.

3.- DEARDORFF T L, OVERSTREET R M. Hysterothylacium and Iheringascaris (both previously =
Thynnascaris) (Nematoda: Anisakidae) from the northern Gulf of Mexico. Proc Biol Soc Wash 1980; 93: 1035-79.

4.- BILQEES F M, KHANUM Z, JEHAN Q. Marine fish nematodes of West Pakistan. I. Description of seven new species from Karachi coast. J Sci Karachi 1971; 1: $175-84$.

5.- CARVALHO-VARELA M, CUNHA-FERREIRA V. Helminth parasites of the common sole, Solea solea, and the Senegalese sole, Sele senegalensis on the Portuguese continental coast. Aquaculture 1987; 67: 135-8.

6.- BRUCE N L, CANNON L R G. Hysterothylacium, Theringascaris and Maricostula new genus, nematodes (Ascaridoidea) from Australian Pelagic marine fishes. J Nat Hist 1989; 23: 1397-441.

7.- RAJYA LAKSHMI I. Hysterothylacium nellorensis sp.nov. (Nematoda: Anisakidae) from freshwater fish, Labeo bogut (Sykes). Geobios New Reports 1996; 15: 77-81.

8.- RAJYA LAKSHMI I. Description of a new species of Hysterothylacium Ward and Magath, 1917 (Nematoda: Anisakidae) from the intestine of marine fish, Nemipterus japonicus. Riv Parassitol 1996; XIII (LVII): 53-60.

9.- PETTER A J, RADUJKOVIC B M. (Nematode parasites of fish in Adriatic Sa) Nematodes parasites de poissons de lamer Adriatique. Bulletin du Muséum Nacional d' Histoire Naturelle A (Zoologie, Biologie et Ecologie Animales) 1986; 8: 487-99.

10.- RAJYA LAKSHMI I, HANUMANTHA RAO K, SHYAMASUNDARI K. Hysterothylacium pseudotumbili n.sp. (Nematoda: Anisakidae) from the marine fishes of Visakhapatnam (Bay of Bengal). Bol Chil Parasitol 1991; 46: 69-73.

11.- RAJYA LAKSHMI I, HANUMANTHA RAO K, SHYAMASUNDARI K. Hysterothylacium neocornatum n.sp. (Nematoda: Anisakidae) from the freshwater fish, Anguilla bicolor bicolor McClalland of Godavari river (Rajahmundry). Riv Parasit 1992; IX(LIII) 2: 157-69.

13.- RAJYA LAKSHMI I. Hysterothylacium kiranii n.sp. (Nematoda: Anisakidae) from the body cavity of Channa (Ophiocephalus) punctatus. Ind J Parasitol 1993; 16(2): 83-83.

13.- RAJYA LAKSHMI I. Description of new species of Hysterothylacium Ward and Magath, 1917 (Nematoda: Anisakidae) from the intestine of the freshwaster fish, Anabas testudineus (Bloch). Riv Parasitol 1992; IX (LVIII) 3: 299-309.

14.- RAJYA LAKSHMI I, HANUMANTHA RAO K, SHYAMASUNDARI K. Hysterothylacium carutti n.sp. (Nematoda: Anisakidae) from the marine fish Johnius carutta Bloch of Bay of Bengal, Visakhapatnam. Uttar Pradesh J Zool 1993; 13: 1-10.

15.- RAJYA LAKSHMI I, HANUMANTHA RAO K, SHYAMASUNDARI K. Hysterothylacium longicaecum n.sp. (Nematoda: Anisakidae) from the intestine and stomach of freshwater fishes of Visakhapatnam. J Parasit Appl Animal Biol 1993; 2: 1-5.

16.- BRIZZOLA SM, TANZOLA RD. Hysterothylacium rhamdiae sp.n. (Ascaridoidea: anisakidae) from a neotropical catfish, Rhamdia sapo (Pisces: Pimelo- 
didae). Memórias do Instituto Oswaldo Cruz 1995; 90 : 349-52.

17.- RAJYA LAKSHMI I. Hysterothylacium channai n.sp. (Nematoda: Anisakidae) form the intestine of Channa pucntatus (Bloch) from Kolleru lake (Andhra Pradesh). Riv Parassitol 1995; XII(LVI) 2: 221-8.

18.- RAJYA LAKSHMI I. Hyserothylacium punctati sp.nov. (Nematoda: Anisakidae) from the stomach of the freshwater fish, Channa punctatus Bloch. Geobios New Reports 1995; 14(2): 123-9.

19.- RAJYA LAKSHMI I. Description of new species of Hysterothylacium Ward and Magath, 1917 (Nematoda: Anisakidae) from the intestine of the freshwater catfish Heteropneustes fossilis (Bloch). Riv Parassitol 1996; XIII(LVII) 2: 169-76.

20.- RAJYA LAKSHMI I. Hysterothylacium narayanensis n.sp. (Nematoda: Anisakidae) from the body cavity of Barbus ticto (Günther). The Uttar Pradesh Zool Soc 1997; 17: 151-5.

21.- MORAVEC F, URAWA S, CORIA C O. Hysterothylacium patagonense n.sp. (Nematoda: Anisakidae) from freshwater fishes in Patagonia, Argentina, with key to the species of Hysterothylacium in American freshwater fishes. Systematic Parasitology 1997; 36: 31-8.

22.- MORAVEC F, NAGASAWA K. Hysterothylacium nipponense nom.n. (Nematoda: anisakidae) for $H$. japonicum Moravec et Nagasawa, 1998 preoccupied by Hysterothylacium japonicum Rajyalakshmi, 1996. Folia Parasitologica 1998; 45: 328.

23.- TORRES P, ANDRADE P, SILVA R. On a new species of Hysterothylacium (Nematoda: Anisakidae) from Cauque mauleanum (Pisces: Atherinidae) by bright field and scanning electron microscopy. Memórias do Instituto Oswaldo Cruz 1998; 93: 745-52.

24.- MORAVEC F, NAGASAWA K. Some anisakid nematodes from marine fishes of Japan and the North Pacific Ocean. J Nat Hist 2000; 34: 1555-74.

Acknowledgements: Thanks are due to Andhra University authorities for providing facilities.

\section{ANNOUNCEMENT}

\section{PARASITOLOGIA LATINOAMERICANA IN INTERNET}

Information about Parasitologla Latinoamericana and its electronic version can be found in: www.scielo.cl 